\title{
[P-W-346] ANTI-OXIDANTS IMPROVE FACTOR VIII FOLDING AND SECRETION AND REDUCE CELL TOXICITY AND INFLAMMATION IN VIVO IN MICE
}

\section{R.J. Kaufman, J. Malhotra, S.W. Pipe, H. Miao. Biological Chemistry and Internal Medicine; Biological Chemistry; Pediatrics, University of Michigan Medical Center, Ann Arbor, United States}

Introduction: Clotting Factor VIII (FVIII) secretion is limited due to protein misfolding in the endoplasmic reticulum (ER). Recently we demonstrated that expression of FVIII, as well as B domain deleted (BDD) FVIII, in the livers of mice activates the Unfolded Protein Response (UPR), an inflammatory response, oxidative stress, and apoptosis. In contrast, a more efficiently secreted form of FVIII, 226/N6 (MIao et al.), did not induce any of these responses. In this study we evaluated the effect of anti-oxidant treatment on these toxic responses and FVIII secretion in mice. Methods: FVIII was expressed in liver by DNA injection of FVIII expression vectors into the tail veins of mice. The anti-oxidant butylated hydroxyanisole (BHA) was added to mouse chow 4 days prior to DNA injection. Cellular responses and and FVIII secretion were studied at $48 \mathrm{hr}$ after DNA injection.

Results: Feeding mice with BHA prevented UPR activation, apoptosis, oxidative stress, and the inflammatory response associated with FVIII and BDD FVIII expression. Surprisingly, BHA feeding also increased secretion of FVIII and BDD factor VIII into the plasma approximatley 3-4 fold, where it had no effect on secretion of 226/N6 FVIII. Finally, BHA feeding increased by 6-fold the secretion of a folding-defective functional FVIII mutant Arg593-Cys that is known to cause hemophilia A. Conclusions: Anti-oxidant treatment prevents oxidative stress and activation of the inflammatory response, the UPR, and apoptosis, and and also increases FVIII secretion. The results implicate the significance of oxidative stress on ER function. Anti-oxidants may be a useful adjuvant to improve FVIII secretion of in gene therapy, as well as improve secretion of folding-defective mutant FVIII molecules in patients with hemophilia A.

References: Miao HZ, Sirachainan N, Palmer L, Kucab P, Cunningham MA, Kaufman RJ, Pipe SW: Bioengineering of coagulation factor VIII for improved secretion. Blood 103:3412-3419, 2004. Kaufman RJ, Malhotra J, Pipe SW, Miao H. ANTI-OXIDANTS IMPROVE FACTOR VIII FOLDING AND SECRETION AND REDUCE CELL TOXICITY AND INFLAMMATION IN VIVO IN MICE. J Thromb Haemost 2007; 5 Supplement 2: P-W-346

Date: Wednesday, July 11, 2007

Session Info: Poster: Secretion and Protein trafficking

Room: Exhibition Area 